\title{
Effect of a pre-exercise hydrocortisone dose on short-term physical performance in female patients with primary adrenal failure
}

\author{
Katerina Simunkova', Nevena Jovanovic ${ }^{2}$, Espen Rostrup ${ }^{3}$, Paal Methlie', \\ Marianne Øksnes ${ }^{1}$, Roy Miodini Nilsen ${ }^{4}$, Hanne Hennø ${ }^{1}$, Mira Tilseth ${ }^{1}$, \\ Kristin Godang ${ }^{5}$, Ana Kovac', Kristian Løvås ${ }^{1,2}$ and Eystein S Husebye ${ }^{1,2}$ \\ ${ }^{1}$ Department of Clinical Science, University of Bergen, N-5021 Bergen, Norway, Departments of ${ }^{2}$ Medicine, \\ ${ }^{3}$ Heart Disease and ${ }^{4}$ Center for Clinical Research Haukeland University Hospital, Bergen, 5021 Bergen, Norway and \\ ${ }^{5}$ Section of Specialized Endocrinology, Department of Endocrinology, Oslo University Hospital Rikshospitalet, \\ N-0027 Oslo, Norway
}

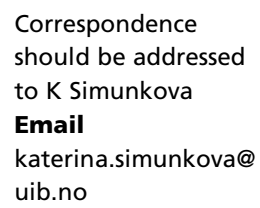

\section{Abstract}

Objective: Many patients with primary adrenal insufficiency (Addison's disease) take extra doses of glucocorticoids during stressful events, but a benefit has not been demonstrated in controlled trials. Here, we investigated the effects of a pre-exercise hydrocortisone dose on cardiorespiratory, hormonal and metabolic parameters in response to short-term strenuous physical activity.

Design: This was a randomized placebo-controlled, cross-over clinical trial.

Participants: Ten women with Addison's disease and 10 age-matched healthy females participated in the study. Measurements: All women in the study underwent maximal incremental exercise testing. A stress dose of $10 \mathrm{mg}$ hydrocortisone or placebo was given $1 \mathrm{~h}$ prior to exercise on two occasions. Blood samples were drawn before, and 0,15 and $30 \mathrm{~min}$ post exercise. Oxygen uptake, maximal aerobic capacity, endocrine and metabolic responses to physical activity, as well as health status by questionnaires were evaluated.

Results: Maximal aerobic capacity and duration of exercise were significantly lower in patients than in healthy subjects and did not improve with the treatment. After an extra hydrocortisone dose serum cortisol was significantly higher than in the healthy subjects $(P<0.001)$. Post-exercise glucose and adrenaline levels were significantly lower and free fatty acids insignificantly higher in patients irrespective of stress dose. Stress dosing did not alter other metabolic or hormonal parameters or quality of life after the exercise.

Conclusions: The patients did not benefit from an extra dose of hydrocortisone in short strenuous exercise. Stress dosing may not be justified in this setting. Whether stress dosing is beneficial in other types of physical activity will have to be examined further.

\section{Introduction}

Addison's disease (AD) is a rare, life-threating disease (1). The current standard replacement therapy is twice or thrice daily hydrocortisone (HC) or cortisone acetate, together with the synthetic mineralocorticoid fludrocortisone (2). Recently, more physiological treatment options (c) 2016 European Society of Endocrinology Printed in Great Britain have been introduced. Once-daily dual-release HC taken upon awakening quickly restores morning cortisol levels and thereafter reproduces the normal gradual decline over the day (3). Continuous subcutaneous HC infusion (CSHI) (4) restores the circadian cortisol rhythm, but not the 
ultradian variation in cortisol (5). None of these treatment modalities restore the acute cortisol response to stress needed to maintain circulation and energy homeostasis. Depending on severity and duration of the stressful event, serum cortisol levels rise to $500-1430 \mathrm{nmol} / \mathrm{l}$ (or 18$52 \mathrm{mg} / \mathrm{dl}$ ) (6), which provide the basis for the recommendation to double or triple the daily dosage during acute stress and illness (7).

Minor stress also normally increases the level of cortisol (6). Many patients regularly increase their dosage during physical exercise or emotional stress. Half of the patients reported taking stress doses during increased stress at work and at home, even without intercurrent illness. Such a practice, if used often enough, might in some cases contribute to long-term metabolic complications (8). Yet other AD patients never take extra doses of HC, except when severely ill (9).

The stress dosage recommendations are highly empirical and the benefit has not been documented in clinical trials so far. A pilot trial tested the efficacy of stress dosing in congenital adrenal hyperplasia $(\mathrm{CAH})$, showing no increase in the exercise capacity $(10,11)$. Here, we investigated whether a $10 \mathrm{mg}$ HC stress dose given $1 \mathrm{~h}$ prior to short-term maximal physical activity would improve physical performance and $\mathrm{VO}_{2 \max }$ in a placebocontrolled cross-over trial.

\section{Subjects and methods}

\section{Design and participants}

This was a randomized, double-blind, two-armed, crossover designed clinical trial, aimed at determining the effects of an extra HC dose on cardiorespiratory, hormonal and metabolic parameters in response to a maximal incremental ergometer cycle test to volitional exhaustion. We hypothesized that AD patients would benefit from $10 \mathrm{mg}$ HC given prior to exercise and that they would reach the same physical activity and stress hormone response as matched healthy subjects. The primary outcome was $\mathrm{O}_{2}$ uptake estimated as maximal aerobic capacity. Secondary endpoints were detailed cardiorespiratory parameters, duration of exercise, post-exercise hypoglycemic events and glycemic variability, endocrine and metabolic responses, and HRQoL evaluated by questionnaires. Eligible patients were identified from our patient registry (Registry of Organ-Specific Autoimmune Diseases) and invited to participate.

Inclusion criteria were females with verified autoimmune $\mathrm{AD}$ with disease duration of more than 1 year.
Since female patients report more fatigue and reduced physical function (9) than males, we elected to include only women. The patients were on stable cortisone acetate and fludrocortisone doses for at least 1 month before the study onset, and kept constant throughout the study. Any concomitant endocrine diseases were on stable treatment during the study period. Fertile woman were either in a luteal or follicular phase of the cycle, and two women were postmenopausal. Exclusion criteria included type 1 diabetes, malignant disease, pregnancy, estrogen treatment, cardiovascular disease including hypertension, lung disease, neuromuscular diseases and pharmacological treatment with glucocorticoids or drugs that interfere with cortisol and catecholamine metabolism. Participants were told to avoid food and drink interfering with steroid and catecholamine metabolism for at least $48 \mathrm{~h}$ and strenuous exercise for at least $24 \mathrm{~h}$ before the study start. Age-matched healthy women (C) were recruited from the general population by poster at the University of Bergen and Haukeland University Hospital.

The patients were assigned a participation number and randomized to any of two treatment sequences (A-B or B-A) by the Haukeland University Hospital Pharmacy. Treatment A was $10 \mathrm{mg}$ HC (two tablets Cortef, Pfizer, $5 \mathrm{mg}$ ), Treatment B was placebo (two placebo tablets). All medication was in gel capsules produced by Kragerø Pharmacy (www.kagero.com) according to the randomization list. Thus, the active and placebo tablets were unidentifiable. All patients and healthy subjects signed informed consent prior to inclusion. The study was approved by the Regional Ethical committee and the National Medicines Agency in Norway (EudraCTnumber2012-005117-40, www.ClinicalTrial.gov ID:NCT01847690). The study was performed according to the principles of Good Clinical Practice (CPMP/ICH/135/95) and the Declaration of Helsinki (1989 version).

\section{Ergometer test and cardiorespiratory assessment}

Prior to the randomization and at least 3 days prior to the first test day, each patient and healthy subject underwent a maximal incremental cycle ergometer test to volitional exhaustion to adapt to the test procedure. The test consisted of a $3 \mathrm{~min}$ warm-up and then gradual increments of load up to the maximum capacity for the patient. The individual work rate increase was calculated by predicted maximal power and designed to elicit maximal effort in $8-12 \mathrm{~min}$. All the participants arrived $1 \mathrm{~h}$ prior to the test. The patients ingested a gel capsule 
(HC or placebo) orally under the supervision of the investigator. The patients underwent the same cycle ergometer test twice, either with active treatment or placebo, separated by at least 1 week. All exercise tests were performed $3 \mathrm{~h}$ after intake of the morning medication. The healthy subjects underwent the cycle ergometer test once without receiving any medication.

Exercise testing was performed according to an incremental ergometer cycle protocol, during which heart rate, blood pressure and ventilatory gas exchange was measured by an ergospirometer with a breathto-breath analyzer (Schiller Cardiovit CS-200 ErgoSpiro/13 Ganzhorn Power Cube). An indwelling catheter was inserted in the forearm at least $30 \mathrm{~min}$ before each test and used to draw blood at baseline and 0, 15 and $30 \mathrm{~min}$ after the end of the test. Saline was administered at a slow rate to maintain an open cannula throughout the test. Serum, plasma and saliva samples were stored at $-80^{\circ} \mathrm{C}$ until the analysis, which was performed in one run.

Measurements included maximal work load, maximum oxygen uptake $\left(\mathrm{VO}_{2 \max }\right),\left(\mathrm{VO}_{2}\right)$, carbon dioxide production $\left(\mathrm{VCO}_{2}\right)$, oxygen uptake per $\mathrm{kg}\left(\mathrm{VO}_{2}\right.$ per $\left.\mathrm{kg}\right)$, heart rate, blood pressure, respiratory exchange ratio $\left(\mathrm{RER}_{\max }\right)$, rating of perceived exertion, exercise duration, duration of recovery, maximum peak of oxygen per pulse, metabolic equivalents (METS) and energy expenditure (EE). Measures at anaerobic threshold (AT) included: $\mathrm{VO}_{2}$, $\mathrm{VO}_{2}$ per $\mathrm{kg}, \mathrm{VCO}_{2}$, heart rate, respiratory exchange ratio, time of the biking, uptake of $\mathrm{O}_{2}$ per pulse and load.

Rating of perceived exertion was performed immediately after the end of each test using the revised Borg scale (12). $\mathrm{O}_{2}$ uptake during the final $20 \mathrm{~s}$ of exercise was used as a measure of $\mathrm{VO}_{2 \max }$. The patients were asked about their opinion about which treatment was given immediately after and the day after each test. Each patient was provided with a diary to record any extra-doses of medication after the exercise.

Hypoglycemic events (blood glucose below $\leq 3.1 \mathrm{mmol} / \mathrm{l}$ ) and glycemic variability were monitored by a continuous glucose monitoring system (CGMS, Dexcom G4 Platium) for $24 \mathrm{~h}$ after each exercise. The CGMS was calibrated 1 day before each test following the standard rules of calibration. Data were downloaded by Dexcom Studio 12.0.3.43 and the night period from $2400 \mathrm{~h}$ till $0600 \mathrm{~h}$ was chosen for evaluation.

\section{Biochemical assays}

Cortisol and cortisone (serum and saliva) were analyzed by liquid chromatography-tandem mass spectrometry (13).
Glucose, insulin, lactate and growth hormone $(\mathrm{GH})$ were analyzed by standard assay used by the Clinical Chemistry Routine laboratory at Haukeland University Hospital (Bergen, Norway). Free fatty acids (FFA) were measured enzymatically on a Hitachi 917 system (Roche Diagnostics, GmbH) using the FFA kit NEFA FS (non-esterified fatty acids) ref.157819910935 from Diasys (Diagnostic System, $\mathrm{GmbH}$, Holzheim, Germany). The plasma for adrenaline and noradrenaline analyses were collected in vacutainer tubes treated with ethylene glycol tetraacetic acid and glutathione, reagent from Sigma-Aldrich (St Louis, MO, USA). A and NA were analyzed by reversed-phase highperformance liquid chromatography (HPLC, Agilent Technologies, Santa Clara, CA, USA) and electrochemical detection (ECD, Antec, Leyden Deacade II SCC, Zoeterwoude, The Netherlands) using a commercial kit (Chromsystems, München, Germany). The intra- and inter-assay coefficients of variation (CV) were 3.9 and $10.8 \%$ respectively. The detection of $\mathrm{A}$ and NA limit was $5.46 \mathrm{pmol} / \mathrm{l}(14,15)$.

\section{Questionnaires}

In the evening after each exercise test, patients completed the two generic HRQoL questionnaires, the Short-Form 36 (SF 36) and AD-specific AddiQoL questionnaire. AddiQoL consists of 30 items with scoring algorithms as described in (16). A higher score indicates a higher level of HRQoL (score range 30-120).

\section{Statistical analysis}

The comparison of the stress dose treatment with placebo treatment and healthy controls from baseline through end of follow-up was done by using linear regression models for repeated measures (i.e. mixed-effects models). The models for biological and glycemic data defined treatment, time and treatment-by-time interaction as fixed effects, whereas a random intercept was specified to account for correlated observations of the same individual. For HRQoL data, observations were only available at the end of follow-up, so no time or treatment-by-time interactions were included when comparing the treatment groups. When a significant period and/or sequence effect in the cross-over design was detected, the comparison of stress dose with placebo was performed alone in a separate model, including period and sequence terms. In situations of substantially skewed data (METS $\left._{\text {max }}, \mathrm{VO} 2 \mathrm{kgAT}, \mathrm{HRAT}\right)$, the mixed models performed poor fit. For these variables and ergometry, we used simple non-parametric methods: Wilcoxon Signed Rank Test for 
Table 1 General characteristics of participants. Data are presented as mean (s.D.) or as percentages.

\begin{tabular}{|c|c|c|}
\hline & Patients & $\begin{array}{l}\text { Healthy } \\
\text { subjects }\end{array}$ \\
\hline Age (years) & $48(15.9)$ & $48.4(15.8)$ \\
\hline BMI $\left(\mathrm{kg} / \mathrm{m}^{2}\right)$ & $22.9(4.6)$ & $24.6(4.8)$ \\
\hline Cortisone acetate daily dose (mg) & $30.1(7.6)$ & 0 \\
\hline Fludrocortisone daily dose $(\mu \mathrm{g})$ & $0.095(0.015)$ & 0 \\
\hline Duration of disease (years) & 1 to 33 & 0 \\
\hline Hypothyroidism & $50 \%$ & 0 \\
\hline Full-time workers & $50 \%$ & $100 \%$ \\
\hline Part-time workers & $40 \%$ & 0 \\
\hline Not working & $10 \%$ & 0 \\
\hline Daily physical activity & $40 \%$ & $80 \%$ \\
\hline Three-times-a-week physical activity & $40 \%$ & $20 \%$ \\
\hline No physical activity & $20 \%$ & 0 \\
\hline $\begin{array}{l}\text { Stress dose during common } \\
\text { illnesses }\end{array}$ & $100 \%$ & 0 \\
\hline $\begin{array}{l}\text { Stress dose before every physical } \\
\text { activity }\end{array}$ & $20 \%$ & 0 \\
\hline $\begin{array}{l}\text { Stress dose before long-lasting } \\
\text { physical activity }\end{array}$ & $20 \%$ & 0 \\
\hline Stress dose before stressful event & $10 \%$ & 0 \\
\hline
\end{tabular}

comparison of stress dose with placebo treatment, and Mann-Whitney $U$ Test for comparison of stress-dose treatment with controls. All regression analyses were performed using Stata/IC version 12.0 (StataCorp LP,
College Station, TX, USA) software for Windows. All $P$ values were two-sided and values $<0.05$ were considered statistically significant. To obtain Sidak-corrected 95\% CI for the predicted mean difference between treatment groups, we performed a post-hoc test for pairwise comparison by using the 'margins' command in Stata. To investigate overall between-treatment change, we used the likelihood ratio test by comparing the log-likelihood between models with and without the treatment-by-time interaction. The likelihood ratio test was also performed to obtain a P value for overall treatment group difference.

\section{Results}

\section{Participants}

Eligible patients were identified in the national Addison's registry and 28 patients were invited by letter to participate. Sixteen patients either did not reply or did not fulfill the inclusion criteria (interfering medication, systemic disease). Twelve patients signed informed consent, one failed to manage the first cycling test due to severe joint pain. Eleven patients were included; one was withdrawn at the end of the study because of

Table 2 Physical and cardiorespiratory parameters in response to a cycle test. Data are presented as observed mean \pm s.E.M. Number of patients included in the analyses were 10 for treatment of HC, 10 for placebo and 10 were healthy subjects.

\begin{tabular}{|c|}
\hline Parameters \\
\hline 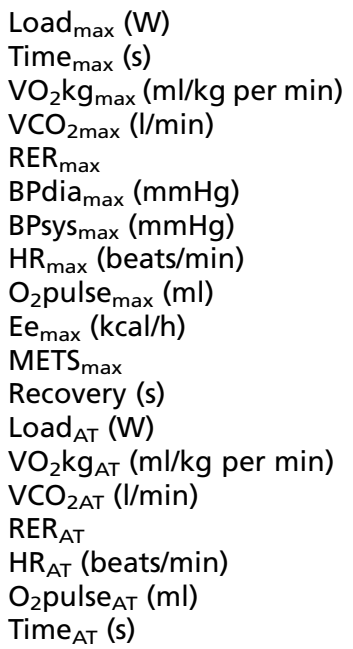 \\
\hline
\end{tabular}

\begin{tabular}{c}
\hline Treatment \\
\hline $141.0 \pm 32.0$ \\
$344.0 \pm 108.0$ \\
$25.7 \pm 8.4$ \\
$1.9 \pm 0.5$ \\
$1.2 \pm 0.1$ \\
$94.2 \pm 8.6$ \\
$186.0 \pm 19.0$ \\
$160.0 \pm 20.0$ \\
$9.8 \pm 1.8$ \\
$453.0 \pm 205.0$ \\
$11.1 \pm 12.3$ \\
$53.0 \pm 24.0$ \\
$99.6 \pm 23.9$ \\
$18.1 \pm 5.5$ \\
$1.1 \pm 0.3$ \\
$0.9 \pm 0.1$ \\
$143.0 \pm 24.0$ \\
$8.1 \pm 1.7$ \\
$228.0 \pm 77.1$ \\
\hline
\end{tabular}

\begin{tabular}{c}
\hline Placebo \\
\hline $142.0 \pm 33.0$ \\
$353.0 \pm 100.0$ \\
$26.6 \pm 8.1$ \\
$2.0 \pm 0.5$ \\
$1.2 \pm 0.1$ \\
$94.7 \pm 11.8$ \\
$192.0 \pm 19.0$ \\
$159.0 \pm 16.0$ \\
$10.7 \pm 2.2$ \\
$529.0 \pm 135.0$ \\
$7.6 \pm 2.3$ \\
$58.0 \pm 22.0$ \\
$104.0 \pm 20.5$ \\
$32.0 \pm 37.2$ \\
$1.2 \pm 0.3$ \\
$0.9 \pm 0.1$ \\
$144.0 \pm 15.0$ \\
$8.7 \pm 2.0$ \\
$249.0 \pm 55.1$ \\
\hline
\end{tabular}

\begin{tabular}{c}
\hline Wilcoxon's test* $^{*}$ \\
\hline 0.6 \\
0.3 \\
0.7 \\
0.2 \\
0.4 \\
1.0 \\
0.2 \\
0.3 \\
0.2 \\
0.2 \\
0.8 \\
0.4 \\
0.9 \\
0.4 \\
0.2 \\
0.7 \\
0.5 \\
0.6 \\
0.4
\end{tabular}

\begin{tabular}{c}
\hline Healthy subjects \\
\hline $186.0 \pm 35.0$ \\
$490.0 \pm 98.0$ \\
$25.7 \pm 8.7$ \\
$2.7 \pm 0.7$ \\
$1.2 \pm 0.1$ \\
$95.0 \pm 13.4$ \\
$195.0 \pm 26.0$ \\
$172.0 \pm 12.0$ \\
$13.5 \pm 3.2$ \\
$726.0 \pm 171.0$ \\
$9.6 \pm 2.1$ \\
$107.0 \pm 32.0$ \\
$137.0 \pm 28.2$ \\
$25.1 \pm 6.2$ \\
$1.7 \pm 0.5$ \\
$0.9 \pm 0.1$ \\
$134.0 \pm 48.0$ \\
$11.8 \pm 2.9$ \\
$354.0 \pm 79.5$ \\
\hline
\end{tabular}

\begin{tabular}{c} 
Mann-Whitney test $^{\dagger}$ \\
\hline 0.01 \\
0.01 \\
0.03 \\
0.005 \\
0.1 \\
0.8 \\
0.3 \\
0.1 \\
0.01 \\
0.005 \\
0.1 \\
0.001 \\
0.009 \\
0.01 \\
0.01 \\
0.7 \\
0.9 \\
0.01 \\
0.004 \\
\hline
\end{tabular}

$\star P$ for difference (Treatment vs Placebo).

${ }^{\dagger} P$ for difference (Treatment vs Healthy subjects).

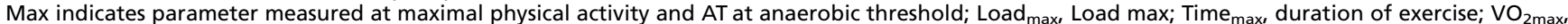
oxygen uptake; $\mathrm{VO}_{2} \mathrm{~kg}_{\max }$, oxygen uptake per $\mathrm{kg}$; $\mathrm{VCO}_{2 \max }$, carbon dioxide production; $\mathrm{RER}_{\max }$, respiratory exchange rate; $\mathrm{BPdia}_{\text {max }}$, peak diastolic blood preassure; $B_{s y s_{\text {max }}}$ peak systolic blood preassure; $\mathrm{HR}_{\max }$, peak heart rate; $\mathrm{O}_{2}$ pulse max $_{\text {maximum }}$ meak of oxygen per pulse; Ee $\mathrm{e}_{\text {max }}$, energetic expenditure max; METS $S_{\max }$ metabolic equivalents max, Recover-Time of recovery. 

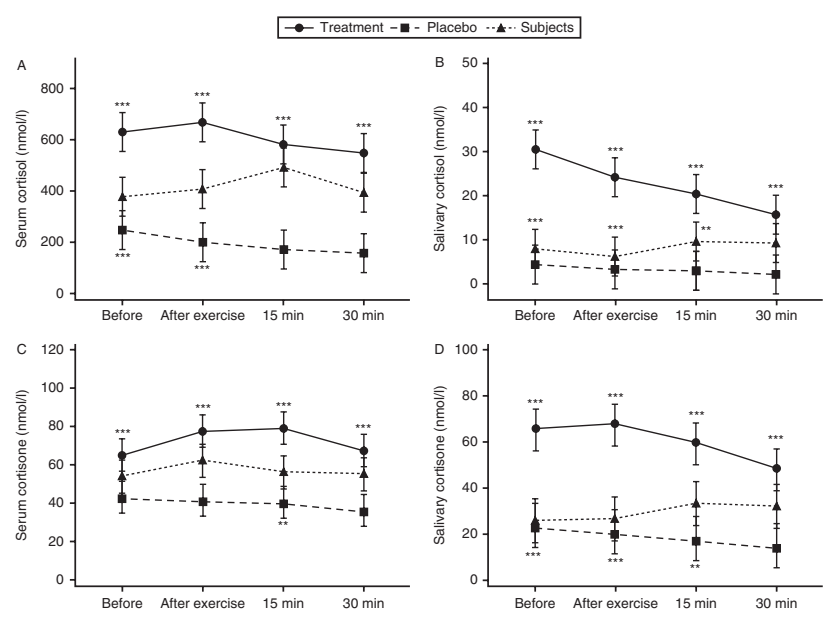

\section{Figure 1}

Serum and salivary cortisol, cortisone in patients and healthy subjects. (A) Serum cortisol $P$ for interaction: 0.08. (B) Salivary cortisol $P$ for interaction: 0.01 . (C) Serum cortisone $P$ for interaction: 0.26 . (D) Salivary cortisone $P$ for interaction: 0.08 . $* * * P \leq 0.001$ for treatment vs placebo. $* * * P \leq 0.001$ for treatment vs subjects. ${ }^{*} P \leq 0.01$ for treatment vs subjects.

non-compliance to the protocol. Fourteen healthy volunteers were invited, but four were excluded during the study because of technical problems, including cannula failure. The healthy subjects were more physically active over the week than the patients. The participant characteristics are summarized in Table 1.

\section{Physical exertion and cardiorespiratory parameters}

The AD women performed significantly worse than the healthy subjects on most parameters of physical activity and cardiorespiratory function during standard ergometer cycle testing, and stress-dose did not improve any of those parameters (Table 2). The patients reached the anaerobic threshold significantly earlier than the healthy subjects, had lower maximum physical capacity, duration of exercise, $\mathrm{VO}_{2 \max }, \mathrm{VCO}_{2}, \mathrm{VO}_{2}$ per $\mathrm{kg}$, uptake of $\mathrm{O}_{2}$ per pulses and EE. On the other hand, the time of recovery was significantly shorter in patients than in the healthy subjects. We did not find any difference in heart rate, blood pressure, respiratory exchange ratio and metabolic equivalents between active and placebo treatment or between patients and healthy subjects.

\section{Hormonal and metabolic response}

Maximum cortisol levels in serum and saliva in HC-treated patients reached almost three times those with placebo and almost twice those of the healthy subjects (Fig. 1). The changes in cortisol were also reflected in the cortisone levels.

Adrenaline (A) and noradrenaline (NA) levels were not affected by the treatment, but the A levels in the patients were significantly lower after the exercise than in the healthy subjects (Fig. 2). The levels of GH, lactate, FFA, blood glucose and insulin were not affected by stress dosing (Table 3). In the patients, the blood glucose and insulin levels seemed to be lower than in the controls and to lack the post-exercise surge, although not statistically significant. The post-exercise nighttime tissue glucose levels were not affected by the administration of an extra dose of hydrocortisone (Fig. 3).

\section{Patient evaluation and HRQoL}

Three patients (30\%) correctly recognized which medication they received, $60 \%$ did not notice any difference and $10 \%$ made the wrong assumption, and we did not find any significant difference between a reply at the day of exercise and the next morning, when only two patients changed their opinion. The HRQoL scores assessed by AddiQoL ( $P$ for differences 0.8 ) and SF-36 ( $P$ for differences $0.4)$ did not differ between the treatments.

\section{Adverse events and extra doses of hydrocortisone after exercise}

No adverse event was noted during the study. None of the patients took extra doses of $\mathrm{HC}$ after the exercise.

\section{Discussion}

Although stress dosing is common among $\mathrm{AD}$ patients, this study of $10 \mathrm{mg} \mathrm{HC}$ dose given to ten female patients

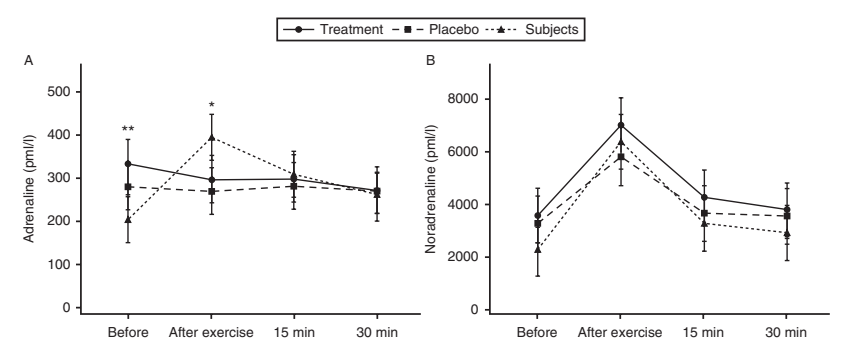

Figure 2

Levels of plasma adrenaline and noradrenaline in patients and healthy subjects. (A) Adrenaline $P$ for interaction was $P \leq 0.001$.

(B) Noradrenaline $P$ for interaction was 0.61 . ${ }^{*} P \leq 0.001$ for treatment vs healthy subjects. ${ }^{\star} P \leq 0.01$ for treatment vs healthy subjects. 


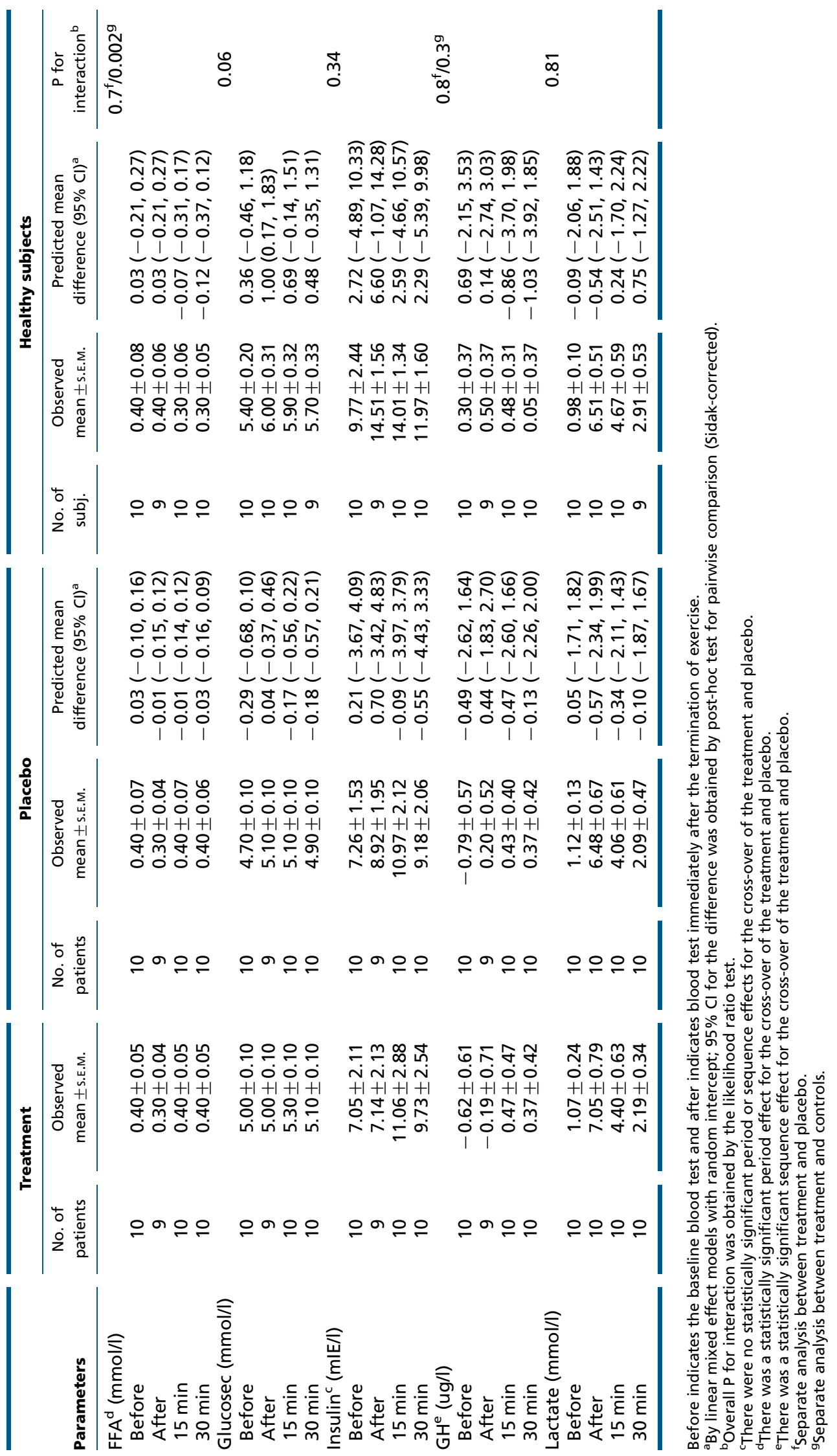




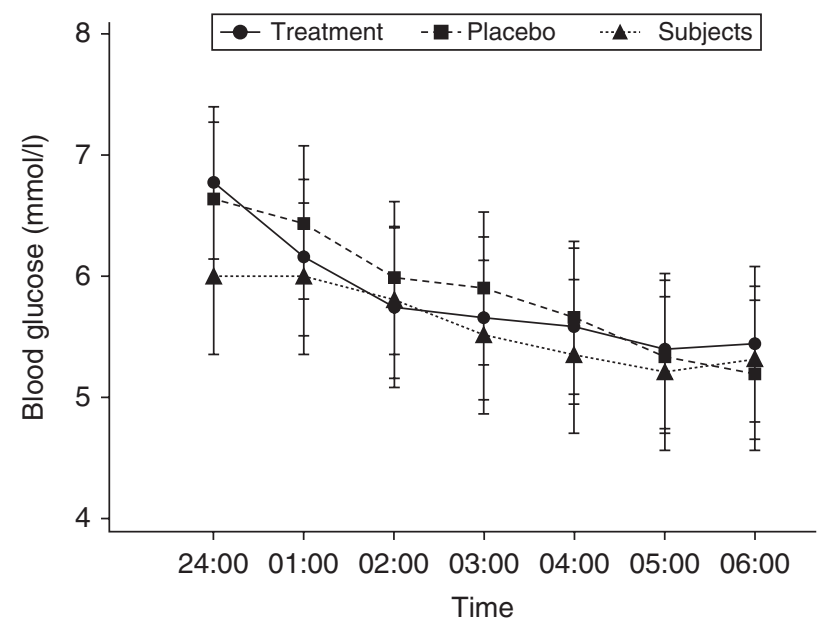

Figure 3

Post-exercise average levels of blood glucose followed up from $2400 \mathrm{~h}$ to $0600 \mathrm{~h}$ in patients and healthy subjects.

$1 \mathrm{~h}$ prior to an ergometer test showed no effect on physical exertion or any cardiorespiratory or metabolic parameter. The patients were not able to tell which treatment they were given, and HRQoL scores were similar on both occasions.

It is remarkable that no effects on physical capacity were noted considering the common use of extra doses during strenuous activity and the ubiquitous actions of cortisol. Whereas the cortisol levels in the AD patients without taking extra doses were lower than in healthy subjects, the levels after extra HC dose were clearly supraphysiological. Glucocorticoid replacement is undoubtedly necessary for survival in $\mathrm{AD}$, and replacement to physiological levels thought to be important for symptom relief and normal HRQoL. However, our results indicate that the cortisol levels may not directly and instantly relate to physical capacity. A relatively small sample may be a limitation of the study, but if individual patients should benefit clinically from such treatment, we anticipated that some effects should be found in a sample of this size. Importantly, the study did not address effects of extra doses in other types of physical stress, i.e., repeated doses and extensive or prolonged physical activity. Moreover, individual HC requirement is influenced by $\mathrm{HC}$ absorption, metabolism and individual sensitivity to glucocorticoids $(17,18)$, and hence proper stress doses would have to be individualized in a clinical setting. Thus, true effects of stress dosing may be concealed by large individual variation and statistical

type II error. The patients were less physically active than controls prior to the trial, possibly contributing to the lower maximal physical capacity achieved by the patients when compared to controls.

Both the results of our study and a similar study in $\mathrm{CAH}(10,11)$ indicate that the function of the adrenal medulla may be more important than the cortisol levels during acute physical stress. Plasma levels of A and NA are very low in healthy subjects at rest (19), but may increase more than 100 times during stress. The rise in A closely correlates with the corticotrophin-releasing hormone (CRH) response to stress, in keeping with cortisol as a major regulator of conversion of NA to A (20). Suppression of the HPA axis by glucocorticoid treatment in healthy subjects downregulates the activity of phenylethanolamine N-methyltransferase (PNMT), resulting in lower basal levels of A. Plasma A is almost exclusively derived from the adrenal medulla, whereas NA is predominantly derived from the sympathetic nervous system (21). However, an extra-adrenal source of A also exists, since the PMNT enzyme is expressed in the heart, kidney, muscles, retina and brain. The extra-adrenal PNMT activity increases after administration of glucocorticoids, and may increase blood pressure and blood glucose (22). Notwithstanding this extra-adrenal source, other studies have found that patients with AD display a 20-50\% reduction of A levels compared to healthy controls under resting conditions (23). Low basal level of A was described also in secondary adrenal insufficiency (24). Levels of $\mathrm{A}$ in both infants and adults with $\mathrm{CAH}$ was significantly lower than in healthy subjects $(22,23$, $24,25)$. The glucocorticoid therapy in CAH had little effect on A levels $(10,26)$. Thus, it is conceivable that in acute and intensive stress, cortisol has a permissive role, whereas the capacity for A increase may be the major limiting factor for physical capacity.

Recently, partial preservation of cortisol secretion in some $\mathrm{AD}$ patients has been documented $(27,28,29)$, which possibly correlates with adrenal medullary function and could partly explain the large diversity in fatigue after stress and propensity to adrenal crisis.

We found an attenuated response in blood glucose after exercise in $\mathrm{AD}$, despite almost doubled cortisol levels after the stress dose. A similar reduced glucose response to maximal exercise was seen in CAH patients, with only $20 \%$ of the normal increase $(26,30,31,32)$. These results indicate that the altered glucose response relates to an impaired A response to stress rather than cortisol levels. $\mathrm{A}$ is one of the principal hormones responsible for shortterm regulation of glucose levels together with insulin, 
glucagon and GH. Reduced glucose levels possibly contribute to the malaise and lack of concentration reported in $\mathrm{AD}$, although the glucose levels observed here were within the normal range (32). A high-calorie diet was shown to reduce symptoms of neuroglycopenia in $\mathrm{AD}$ (33), and thus it is conceivable that oral supply of carbohydrates might be of more help in stress events than HC. Children with AD are more prone towards hypoglycemic events than adults, which may relate to an impaired A response, but also to carbohydrate intake and reserves (11).

Cortisol has well known effects on glucose levels, and cortisol deficiency during daytime exercise might lead to a delayed hypoglycemic response. In a recent study, we found that the glucose levels in $\mathrm{AD}$ patients on conventional replacement therapy declined over the night and reached the lowest level around $0800 \mathrm{~h}$. This glucose decline was counteracted by treatment with continuous subcutaneous hydrocortisone infusion, which restored the cortisol levels to normal through the night (34). Here, we postulated that without the extra dose of HC the patients would experience lower glucose levels than the controls during the night following the exercise, which might be alleviated by the stress dose. However, we found no difference in nighttime glucose levels, either between the treatments or between patients and controls.

In conclusion, this study did not find any benefit of a stress-dose of $10 \mathrm{mg}$ of $\mathrm{HC}$, but revealed differences between patients with $\mathrm{AD}$ and healthy volunteers in adrenaline and glucose responses that may explain the reduced acute physical capacity observed in patients with $\mathrm{AD}$. The results do not lend support to frequent use of stress dosing during short-term strenuous physical activity. Whether stress-dosing is beneficial if given otherwise and during longer-lasting physical activity will have to be investigated further in future trials.

\section{Declaration of interest}

The authors declare that there is no conflict of interest that could be perceived as prejudicing the impartiality of the research reported.

\section{Funding}

The study has been supported by Helse Bergen, Norway.

\section{Author contribution statement}

E S Husebye, K Løvås, K Simunkova, E Rostrup, N Jovanovic, P Methlie, $\mathrm{K}$ Godang and $\mathrm{M} \varnothing \mathrm{ksnes}$ designed the survey, and contributed to the interpretation of the data. The statistical analysis was performed by R M Nilsen. The study was performed K Simunkova, N Jovanovic, H Hennø, $M$ Tilseth and A Kovac. The manuscript was written by $K$ Simunkova and
$\mathrm{N}$ Jovanovic and all authors read, discussed and approved the final manuscript.

\section{Acknowledgements}

We thank the nurses Irene Tarlebø Drotningsvik and Berit Magnus at the Endocrine outpatient clinic and Heart department, and the technician Elisabeth Tombra Halvorsen for her help with organizing the trial. We also thank professor Rolf Kristian Berge and the technician Liv Kristine Oysad for the lipids analyses. We thank Ingunn Heie Anundskås and Kristin Østervold Odfjell, Innovest AS, Bergen for monitoring the clinical trial. The trial was supported by a research grant from the Regional Health authorities of Western Norway.

\section{References}

1 Dunlop D. Eighty-six cases of Addison's disease. BMJ 19631 887-891. (doi:10.1136/bmj.2.5362.887)

2 Neary N \& Nieman N. Adrenal insufficiency: etiology, diagnosis and treatment. Current Opinion in Endocrinology, Diabetes, and Obesity 2010 17 217-223. (doi:10.1097/MED.0b013e328338f608)

3 Johannsson G, Nilsson AG, Bergthorsdottir R, Burman P, Dahlqvist P, Ekman B, Engström BE, Olsson T, Ragnarsson O, Ryberg $\mathrm{M}$ et al. Improved cortisol exposure-time profile and outcome in patients with adrenal insufficiency: a prospective randomized trial of a novel hydrocortisone dual-release formulation. Journal of Clinical Endocrinology and Metabolism 201297 473-481. (doi:10.1210/jc.2011-1926)

4 Øksnes M, Björnsdottir S, Isaksson M, Methlie P, Carlsen S, Nilsen RM, Broman JE, Triebner K, Kämpe O, Hulting AL et al. Continuous subcutaneous hydrocortisone infusion versus oral hydrocortisone replacement for treatment of Addison's disease: a randomized clinical trial. Journal of Clinical Endocrinology and Metabolism 201499 1665-1674. (doi:10.1210/jc.2013-4253)

5 Lightman S \& Terry JR. The importance of dynamic signalling for endocrine regulation and drug development: relevance for glucocorticoid hormones. Lancet. Diabetes \& Endocrinology 20142 593-599. (doi:10.1016/S2213-8587(13)70182-7)

6 Chernow B, Alexander HR, Smallridge RC, Thompson WR, Cook D, Beardsley D, Fink MP, Lake CR \& Fletcher JR. Hormonal responses to graded surgical stress. Archives of Internal Medicine 1987147 1273-1278. (doi:10.1001/archinte.1987.00370070087013)

7 Husebye ES, Allolio B, Arlt W, Badenhoop K, Bensing S, Betterle C, Falorni A, Gan EH, Hulting AL, Kasperlik-Zaluska A et al. Consensus statement on the diagnosis, treatment and follow-up of patients with primary adrenal insufficiency. Journal of Internal Medicine 2014275 104-115. (doi:10.1111/joim.12162)

8 Zueger T, Kirchner P, Herren C, Fischli S, Zwahlen M, Christ E \& Stettler C. Glucocorticoid replacement and mortality in patients with non-functioning pituitary adenoma. Journal of Clinical Endocrinology and Metabolism 201297 E1938-E1942. (doi:10.1210/jc.2012-2432)

9 Erichsen MM, Løvås K, Fougner KJ, Svartberg J, Hauge ER, Bollerslev J, Berg JP, Mella B \& Husebye ES. Normal overall mortality rate in Addison's disease, but young patients are at risk of premature death. European Journal of Endocrinology/European Federation of Endocrine Societies 2009160 233-237. (doi:10.1530/EJE-08-0550)

10 Weise M, Drinkard B, Mehlinger SL, Holzer MS, Eisenhofer G, Charmandari E, Chrouso GP \& Merke DP. Stress dose of hydrocortisone is not beneficial in patients with classic congenital adrenal hyperplasia undergoing short-term, high-intensity exercise. Journal of Clinical Endocrinology and Metabolism 200489 3679-3684. (doi:10.1210/jc. 2003-032051)

11 Weise M, Mehlinger SL, Drinkard B, Rawson E, Charmandari E, Hiroi M, Eisenhofer G, Yanovski JA, Chrousos GP \& Merke DP. Patients with 
classic congenital adrenal hyperplasia have decrease depinephrine reserve and defective glucose elevation in response to high-intensity exercise. Journal of Clinical Endocrinology and Metabolism 200489 591-597. (doi:10.1210/jc.2003-030634)

12 Borg GA. Psychophysical bases of perceived exertion. Medicine and Science in Sports and Exercise 198214 377-381.

13 Methlie P, Hustad SS, Kellmann R, Almås B, Erichsen MM, Husebye E \& Løvås K. Multisteroid LC-MS/MS assay for glucocorticoids and androgens, and its application in Addison's disease. Endocrine Connections 20132 125-136. (doi:10.1530/EC-13-0023)

14 Hjemdahl P. Catecholamine measurements by high-performance liquid chromatography. American Journal of Physiology 1984247 E13-E20.

15 Tsunoda M. Recent advances in methods for the analysis of catecholamines and their metabolites. Analytical and Bioanalytical Chemistry 2006386 506-514. (doi:10.1007/s00216-006-0675-z)

16 Løvås K, Curran S, Øksnes M, Husebye ES, Huppert FA \& Chatterjee VK. Development of a disease-specific quality of life questionnaire in Addison's disease. Journal of Clinical Endocrinology and Metabolism 2010 95 545-551. (doi: 10.1210/jc.2009-1711)

17 Ross IL, Levitt NS, Van der Merwe L, Schatz DA, Johannsson G, Dandara C, Pillay TS \& Blom DJ. Investigation of glucocorticoid receptor polymorphisms in relation to metabolic parameters in Addison's disease. European Journal of Endocrinology/European Federation of Endocrine Societies 2013168 403-412. (doi:10.1530/EJE-12-0808)

18 Ross IL, Dandara C, Swart M, Lacerda M, Schatz D \& Blom DJ. $9 \beta$ Polymorphism of the glucocorticoid receptor gene appears to have limited impact in patients with Addison's disease. PLOS ONE 20149 e86350. (doi:10.1371/journal.pone.0086350)

19 Goldstein DS. Catecholamines 101. Clinical Autonomic Research 201020 331-352. (doi:10.1007/s10286-010-0065-7)

20 Bornstein ME \& Bornstein SR. Cross-talk between adrenal medulla and adrenal cortex in stress. Annals of the New York Academy of Sciences 2008 1148 112-117. (doi:10.1196/annals.1410.053)

21 Wurtman RJ \& Axelfor J. Control of enzymatic synthesis of adrenaline in the adrenal medulla by adrenal cortical steroids. Journal of Biological Chemistry 1966241 2301-2305.

22 Kennedy B, Elayan H \& Ziegler MG. Glucocorticoid hypertension and nonadrenal phenylethanolamine N-methyltransferase. Hypertension 199321 415-419. (doi:10.1161/01.HYP.21.4.415)

23 Bornstein SR, Breidert M, Ehrhart-Bornstein M, Kloos B \& Scherbaum WA. Plasma catecholamines in patients with Addison's disease. Clinical Endocrinology 199542 215-218. (doi:10.1111/j.13652265.1995.tb01866.x)

24 Zuckerman-Levin N, Tiosano D, Eisenhofer G, Bornstein S \& Hochberg Z. The importance of adrenocortical glucocorticoids for adrenomedullary and physiological response to stress: a study in isolated glucocorticoid deficiency. Journal of Clinical Endocrinology and Metabolism 200186 5920-5924. (doi:10.1210/jcem.86.12.8106)
25 Kim MS, Ryabets-Lienhard A, Bali B, Lane CJ, Park AH, Hall S \& Geffner ME. Decreased adrenomedullary function in infants with classical congenital adrenal hyperplasia. Journal of Clinical Endocrinology and Metabolism 201499 E1597-E1601. (doi:10.1210/jc.2014-1274)

26 Green-Golan L, Yates C, Drinkard B, VanRyzin C, Eisenhofer G, Weise M \& Merke DP. Patients with classic congenital adrenal hyperplasia have decreased epinephrine reserve and defective glycemic control during prolonged moderate-intensity exercise. Journal of Clinical Endocrinology and Metabolism 200792 3019-3024. (doi:10.1210/jc.2007-0493)

27 Methlie P, Husebye EE, Hustad S, Lien EA \& Løvås K. Grapefruit juice and licorice increase cortisol availability in patients with Addison's disease. European Journal of Endocrinology/European Federation of Endocrine Societies 2011165 761-769. (doi:10.1530/EJE-11-0518)

28 Gan EH, MacArthur K, Mitchell AL, Hughes BA, Perros P, Ball SG, James RA, Quinton R, Chen S, Furmaniak J et al. Residual adrenal function in autoimmune Addison's disease: improvement after tetracosactide (ACTH1-24) treatment. Journal of Clinical Endocrinology and Metabolism 201499 111-118. (doi:10.1210/jc.2013-2449)

29 Pearce SH, Mitchell AL, Bennett S, King P, Chandran S, Nag S, Chen S, Smith BR, Isaacs JD \& Vaidya B. Adrenal steroidogenesis after B lymphocyte depletion therapy in new-onset Addison's disease. Journal of Clinical Endocrinology and Metabolism 201297 E1927-E1932. (doi:10.1210/jc.2012-1680)

30 Merke DP, Chrousos GP, Eisenhofer G, Weise M, Keil MF, Rogol AD, Van Wyk JJ \& Bornstein SR. Adrenomedullary dysplasia and hypofunction in patients with classic 21-hydroxylase deficiency. New England Journal of Medicine 2000343 1362-1368. (doi:10.1056/ NEJM200011093431903)

31 Verma S, Green-Golan L, VanRyzin C, Drinkard B, Mehta SP, Weise M, Eisenhofer G \& Merke DP. Adrenomedullary function in patients with nonclassic congenital adrenal hyperplasia. Hormone and Metabolic Research 201042 607-612. (doi:10.1055/s-0030-1253385)

32 Clayton R, Burden AC, Schrieber V \& Rosenthal FD. Secondary pituitary hyperplasia in Addison's disease. Lancet 19772 954-956. (doi:10.1016/ S0140-6736(77)90891-1)

33 Klement J, Hubold C, Cords H, Oltmanns KM, Hallschmid M, Born J, Lehnert H \& Peters A. High-calorie glucose-rich food attenuates neuroglycopenic symptoms in patients with Addison's disease. Journal of Clinical Endocrinology and Metabolism 201095 522-528. (doi:10.1210/jc.2009-1752)

34 Björnsdottir S, Øksnes $\mathrm{M}$, Isaksson $\mathrm{M}$, Methlie P, Nilsen RM, Hustad S, Kämpe $\mathrm{O}$, Hulting $\mathrm{AL}$, Husebye ES, Løvås $\mathrm{K}$ et al. Circadian hormone profiles and insulin sensitivity in patients with Addison's disease: a comparison of continuous subcutaneous hydrocortisone infusion with conventional glucocorticoid replacement therapy. Clinical Endocrinology 201583 28-35. (doi:10.1111/ cen.12670)

Received 25 June 2015

Revised version received 15 October 2015

Accepted 21 October 2015 